\title{
Dos fragmentos en arameo cristiano-palestinense del libro del Génesis procedentes de la Mezquita de los Omeyas de Damasco*
}

Juan Pedro Monferrer-Sala***

Universidad de Córdoba

ORCID: 0000-0001-9979-1890

En este artículo analizamos dos fragmentos que contienen los textos de Gn 19,1-5 y Gn 19,7-10. Se trata de dos traducciones realizadas en dialecto arameo cristiano palestinense a partir de un texto griego perteneciente a la versión de la Septuaginta. Sin embargo, como tratamos de demostrar los traductores de estas versiones hubieron de utilizar más textos junto con su Vorlage griega con los que revisaron la traducción destinada a la población del medio rural entre los que desarrollaban su labor pastoral los monjes que utilizaron esta versión.

Palabras clave: Traducción; Antiguo Testamento; LXX; Pešit țā; arameo cristiano palestinense; griego; melkitas; Palestina.

Two Fragments in Christian Palestinian Aramaic of the Book of Genesis from the Umayyad Mosque in Damascus.- Our aim in the present article is to analyze two fragments that contain the texts of Gn 19,1-5 and Gn 19,7-10. These are two translations rendered into Christian-Palestinian Aramaic dialect from a Greek text belonging to the Septuagint version. However, as we try to show the translators of these versions used additional texts along with their Greek Vorlage to revise the translation intended for the rural population among which the monks who used this version developed their pastoral work.

Keywords: Translation; Old Testament; LXX; Peshịttā; Christian-Palestinian Aramaic; Greek; Melkites; Palestine.

* Este trabajo se enmarca en el Proyecto de Investigación FFI2014-53556-R: «Estudio y Edición de manuscritos bíblicos y patrísticos griegos, árabes y latinos», financiado por el Ministerio español de Economía y Competitividad.

**ff1mosaj@uco.es

Copyright: (C) 2017 CSIC. Este es un artículo de acceso abierto distribuido bajo los términos de una licencia de uso y distribución Creative Commons Attribution (CC-by) España 3.0. 


\section{INTRODUCCIÓN}

La expresión «arameo cristiano palestinense» (en adelante, ACP) ${ }^{1}$ es una de las denominaciones más recientes, junto con el de «arameo melkita», utilizadas para referirse a una variedad de arameo tardío utilizado en Palestina por esta comunidad entre los siglos V a XIII, que, fijado en un tipo de escritura cercano al estrangelo ${ }^{2}$, exhibe muchas de las características del arameo judío palestinense y del arameo samaritano ${ }^{3}$.

Desde el siglo IV d.C. en adelante el uso del arameo en Palestina y Transjordania, así como en los centros monásticos, convivió, incluso en una situación de bilingüismo, con la lengua árabe ${ }^{4}$, cuya influencia se deja notar en $\mathrm{ACP}^{5}$. Los habitantes de Jerusalén en el siglo IV hablaban tanto griego como arameo y las versiones de los textos bíblicos conservados en ACP fueron realizadas a partir de originales griegos que hay que identificar con el texto de la Septuaginta (LXX). Estas traducciones, junto con otros textos religiosos, parece que sirvieron a las labores pastorales que realizaban los monjes melkitas entre la población cristiana aramea. A partir de una información facilitada por Egeria (s. IV d.C.) parece que un obispo grecoparlante era acompañado por un presbítero, que traducía

\footnotetext{
${ }^{1}$ Theodor NÖLDEKE, «Über den christlich-palästinischen Dialekt», Zeitschrift der deutschen morgenländischen Gesellschaft XXII (1868) págs. 443-527.

Alain Desremaux, «The Birth a New Aramaic Script in Bilad al-Sham at the End of the Byzantine Period», en The History of Bilād al-Shām during the Umayyad Period. Proceedings of the Third Symposium, eds. M. Adnan BaKHIT y Robert ScHICK (Amman: University of Jordan Press, 1989) págs. 32-36. Para una clasificación paleográfica de los manuscritos, véase Alain DesRemaux, «Les manuscrits syro-palestiniens: propositions pour des comparisons», en III Symposium Syriacum 1980: Les contacts du monde syriaque avec les autres cultures (Goslar 7-11 Septembre 1980), édité par René LAVENANT (Roma: Pontificium Institutum Studiorum Orientalium, 1983) págs. 343-347.

Matthew Morgenstern, «Christian Palestinian Aramaic», en The Semitic Languages: An International Handbook, edited by Stefan Weninger, in collaboration with Geoffrey Khan, Michael P. Streck and Janet C. E. Watson (Berlin - Boston: De Gruyter Mouton, 2011) págs. 628-637.

${ }^{4}$ Véase al respecto Juan Pedro Monferrer-Sala, «Between Hellenism and Arabicization. On the Formation of an Ethnolinguistic Identity of the Melkite Communities in the Heart of Muslim Rules», Al-Qanțara 33:2 (2012) págs. 445-471.

${ }^{5}$ Desremaux, «The Birth a New Aramaic Script» págs. 29-31; Sidney H. Griffith, «From Aramaic to Arabic: The Languages of the Monasteries of Palestine in the Byzantine and Early Islamic Periods», Dumbarton Oaks Papers 51 (1997) págs. 16-24.
} 
tanto las lecciones de la Escrituras como los sermones correspondientes a ACP para que todos pudieran entenderlo ${ }^{6}$. A partir del s. VIII el arameo dejó paso al árabe que se convirtió en la lingua franca de los melkitas ${ }^{7}$.

Entre el escaso número de los textos del Antiguo Testamento que han llegado hasta nosotros ${ }^{8}$ en $\mathrm{ACP}^{9}$ se encuentran dos fragmentos procedentes de la Mezquita de los Omeyas de Damasco ${ }^{10}$, que tienen un especial

${ }^{6}$ Sebastian P. BRock, «The Palestinian Syriac Version», en The Early Versions of the New Testament: Their Origin, Transmission, and Limitations, ed. Bruce M. MetzGER (Oxford: Clarendon Press, 1977) págs. 75-82: pág. 77.

7 Joshua BLAU, «A Melkite Arabic literary 'lingua franca' from the second half of the first millennium», Bulletin of the School of Oriental and African Studies 57 (1994) págs. 14-16; GRIFFITH, «From Aramaic to Arabic» págs. 24-30.

${ }^{8}$ George Henry Gwilliam, F. Crawford Burkitt y John F. Stenning, Biblical and Patristic Relics of the Palestinian Syriac Literature from mss. in the Bodleian Library and in the Library of Saint Catherine on Mount Sinai (Oxford: Clarendon Press, 1896) págs. 9-44; Agnes Smith LewIs, y Margaret Dunlop GiBson, Palestinian Syriac Texts from Palimpsest Fragments in the Taylor-Schechter Collection (Cambridge: Cambridge University Press, 1900; reimp. Piscataway, NJ: Gorgias Press, 2005) págs. 2-43, 106-111; Agnes Smith LewIs, An Appendix of Palestinian Syriac Texts (London: C. J. Clay and Sons, 1902) págs. xv-xxvi, qjw-qjt; Hugo Duensing, Christlich-palästinisch-aramäische Texte und Fragmente (Göttingen: Vandenhoeck und Ruprecht 1906) págs. 113-127, 153; Friedrich Schulthess, Christlich-palästinische Fragmente aus der Omajjaden-Moschee zu Damaskus, ed. de F. Schulthess (Berlin: Weidmannsche Buchhandlung, 1905; Jerusalem: Raritas, 1971) págs. 19-40; Moshe Goshen-Gottstein, The Bible in the Syropalestinian Version. Part. One, Pentateuch and Prophets (Jerusalem: Magnes Press, 1973); Moshe Goshen-GotTsteIn, The Bible in the Syropalestinian Version. Part Two, Psalms (Jerusalem: Magnes Press, 2009); Christa Müller-Kessler y Michael SoKoloff, A Corpus of Christian Palestinian Aramaic. Volume I. The Christian Palestinian Aramaic Old Testament and Apocrypha Version from the Early Period (Gröningen: Styx Publications 1997).

9 Acerca de este registro, véase Christa Müller-Kessler, Grammatik des ChristlichPalästinisch-Aramäischen. I. Schriftlehre, Lautlehre, Formenlehre (Hildesheim - Zürich New York: Gregor Olms, 1991) págs. 1-8 y Friedrich Schulthess, Grammatik des ChristlichPalästinischen Aramäisch, ed. Enno LitTMAnN, con notas de Theodor NöLDEKE y el editor (Tübingen: J.C.B. Mohr, 1924; reimp. Hildesheim: Georg Olms, 1965) págs. 1-4. También Klaus Beyer, The Aramaic Language: Its Distribution and Subdivisions. Translated from the German by John F. HEALEY (Göttingen: Vendenhoeck \& Ruprecht, 1986) págs. 51-53: 36, y Christa Müller-KessLer, «Christian Palestinian Aramaic and Its Significance to the Western Aramaic Dialect Group», Journal of the American Oriental Society 119:4 (1999) págs. 631-636.

${ }^{10} C f$. fragmentos griegos de la LXX en Kurt TREU, Majuskelbruchtücke der Septuaginta aus Damaskus (Göttingen: Vandenhoeck \& Ruprecht, 1966), con alusión a los fragmentos siriacos y árabes melkitas en págs. 3-4. 
interés para el campo de los estudios bíblicos. Se da la circunstancia de que en la actualidad se desconoce el paradero tanto estos dos fragmentos como del resto de textos procedentes de esta Mezquita ${ }^{11}$. Paradójicamente sucede lo mismo con otro fragmento procedente del mismo lugar: una versión bilingüe greco-árabe del salmo 28 (según la LXX) en el que el texto árabe cristiano fue fijado en caracteres griegos unciales ${ }^{12}$.

\section{FRAGMENTOS}

Los dos fragmentos, en un palimpsesto sobre pergamino con medidas de 20x16 $\mathrm{cm}^{13}$, contienen respectivamente los textos de $\mathrm{Gn}$ 19,1-5 (frag. $\mathrm{I}^{\mathrm{r}}$ ) y Gn 19,7-10 (frag. $\mathrm{I}^{\mathrm{v}}$ ) y han sido publicados sucesivamente por Schulthess, Goshen-Gottstein y Müller-Kessler y Sokoloff ${ }^{14}$. En la transcripción de los textos seguimos la disposición original de los mismos en dos columnas, reproduciendo la última edición aparecida de los dos fragmentos en $\mathrm{ACP}^{15}$, cotejada con la que realizara Schulthess en caracteres siriacos occidentales $(\text { serto } \overline{0})^{16}$, con una adición nuestra señalada en la nota correspondiente.

Frag. I ${ }^{\mathrm{r}}$

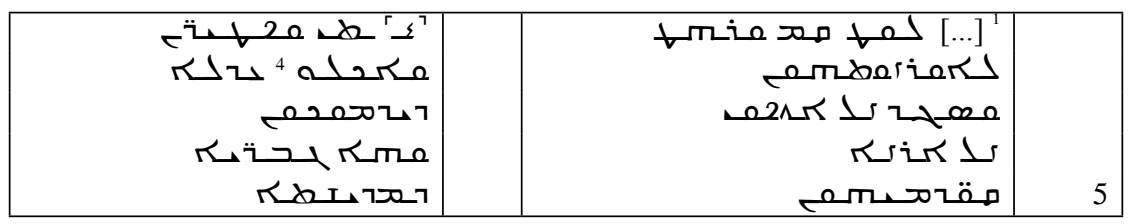

${ }^{11}$ Müller-Kessler y SoKoloff, A Corpus of Christian Palestinian Aramaic. Volume I, págs. 3 y 232.

${ }^{12}$ Bruno VIOLET, «Ein zweisprachiges Psalmfragment aus Damascus», Orientalistische LiteraturZeitung 4 (1901) cols. 384-403, 425-441 y 475-488.

${ }^{13}$ Schulthess, Christlich-palästinische Fragmente, pág. 11.

${ }^{14}$ Schulthess, Christlich-palästinische Fragmente, págs. 19-20, con fotografía de los dos fragmentos en pág. 134; Goshen-GotTsteIn, The Bible in the Syropalestinian Version. Part. I, págs. 11-12; Müller-Kessler y Sokoloff, A Corpus of Christian Palestinian Aramaic. Volume I, págs. 17-18.

${ }^{15}$ Müller-Kessler y SoKoloff, A Corpus of Christian Palestinian Aramaic. Volume I, págs. 17-18.

${ }^{16}$ Schulthess, Christlich-palästinische Fragmente, págs. 19-20. 


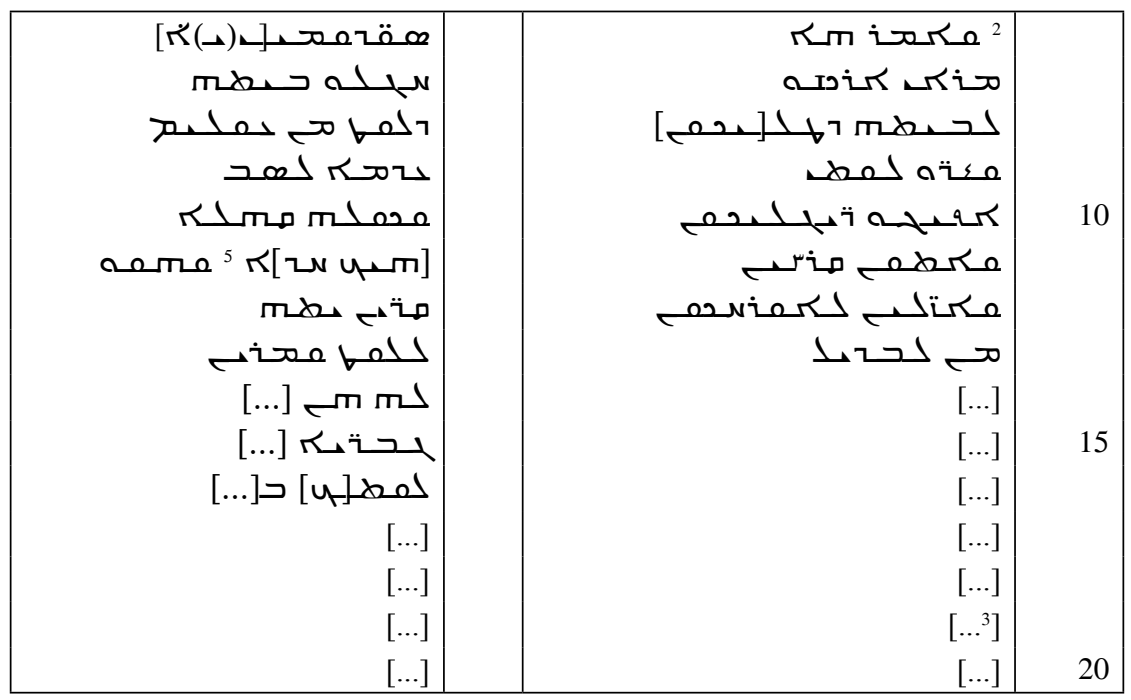

Frag. I

\begin{tabular}{|c|c|c|}
\hline 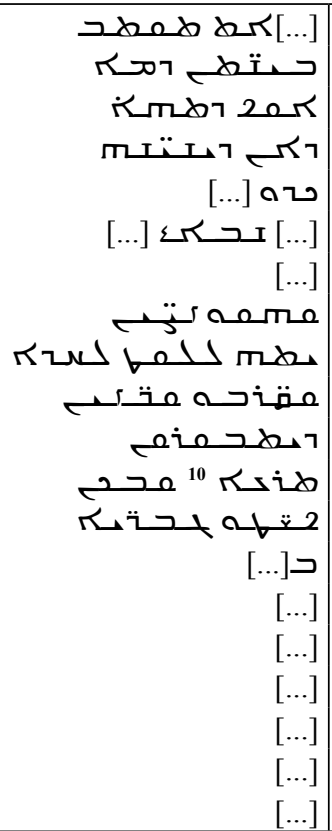 & 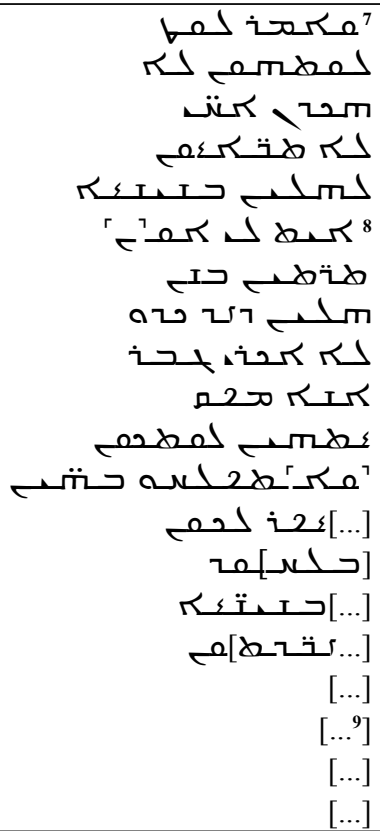 & 10 \\
\hline
\end{tabular}




\section{ANÁLISIS FILOLÓGICO}

Los textos conservados en las traducciones que fueron realizadas en este dialecto arameo utilizado por los cristianos melkitas de Palestina, la mayoría de ellos procedentes del Monasterio de Santa Catalina, en el Monte Sinaí y de la Guenizá de El Cairo, corresponden a traducciones realizadas en el siglo VI d.C. a partir del griego, concretamente de la versión representada por la $\mathrm{LXX}^{17}$, aunque como trataremos de demostrar los traductores de estas versiones hubieron de utilizar más textos junto con su Vorlage para ultimar su traducción final. Esta variedad de textos utilizados puede ser semejante a la descrita para los materiales neotestamentarios que nos han llegado en $\mathrm{ACP}^{18}$.

Los dos fragmentos objeto del presente estudio, junto con el resto de materiales editados, han merecido la atención lingüística (limitada meramente a compilaciones léxicas $)^{19}$, pero en cambio no han recibido hasta el momento un estudio detallado de la naturaleza de las traducciones ${ }^{20}$, la relación con su correspondiente Vorlage y las posibles influencias procedentes de otros textos, ya sean otras versiones o comentarios, que ayuden a poder situar a estos y el resto de los fragmentos en su correcto contexto textual y lingüístico ${ }^{21}$.

El contexto lingüístico, más concretamente plurilingüe, en el que desarrollaron su actividad intelectual los traductores melkitas es de enorme importancia para poder entender el contexto de las traducciones que se llevaron a cabo en diversas lenguas (griego, ACP, siriaco, árabe y armenio) en el seno de los monasterios de esta comunidad dentro de un continuum temporal que abarca varios siglos y relaciona varias

${ }^{17}$ Natalio FERnÁNDEZ MARCos, Introducción a las versiones griegas de la Biblia (2 ${ }^{\mathrm{a}}$ ed. revisada y aumentada, Madrid: Consejo Superior de Investigaciones Científicas, 1998) pág. 356.

${ }^{18}$ Brock, «The Palestinian Syriac Version», págs. 75-82.

19 Cf. Morgenstern, «Christian Palestinian Aramaic», pág. 634, §5.3.9.

${ }^{20}$ Para la producción de trabajos críticos sobre los materiales ACP, véase Sebastian P. Brock, Syriac Studies: A Classified Bibliography (1960-1990) (Kaslik: Université Saint-Esprit, 1996) y la serie de compilaciones bibliográficas publicadas por bloques de cinco años en la revista Parole de l'Orient 23 (1998) págs. 241-357 (1990-95); 29 (2004) págs. 263-410 (1996-2000); 33 (2008) págs. 281-446 (2001-5), y 38 (2013) págs. 241-452 (2006-2010) bajo el epígrafe «Christian Palestinian Aramaic».

${ }^{21} C f$. Morgenstern, «Christian Palestinian Aramaic», pág. 632, §4. 
lenguas $^{22}$. Ni que decir tiene que la conexión entre los textos en diversas lenguas generó un enorme rendimiento intelectual y lingüístico, sobre todo gracias a la relación que se produjo a través de traducciones llevadas a cabo del griego a ACP, del griego al siriaco, del griego al árabe, así como el que se dio del siriaco al árabe y tal vez, aunque este es un asunto que aún debe ser dilucidado, de ACP al árabe.

A tenor de lo anterior, es obvio que los datos obtenidos del análisis traductológico resultarán de gran interés, ya que como podemos entrever estos son susceptibles de ser aprovechados en el estudio de las versiones árabes cristianas realizadas a partir de Vorlagen arameas ${ }^{23}$, tanto siriacas como $\mathrm{ACP}^{24}$, que en el caso concreto que nos ocupa queda circunscrito al libro del Génesis.

En el análisis que realizamos de la traducción en ACP, el texto griego de la LXX que reproducimos corresponde a la edición de Wevers ${ }^{25}$. Igualmente, el texto siriaco de la Peši țta corresponde a la edición del Instituto de la Pešit țtā de Leiden ${ }^{26}$ y para la Vulgata utilizamos la edición de Fischer $^{27}$. Para el resto de materiales utilizados (siriacos y árabes) indicamos en nota la edición correspondiente, salvo en aquellos casos en los que nos servimos de materiales manuscritos aún inéditos: Sin. ar. 2 = Sinaí árabe 2 (siglo X), Sin. ar. 4 = Sinaí árabe 4 (s. X) y Bodl. $258=$ Oxford, Bibl. Bodleiana 258 (siglo XIII) ${ }^{28}$.

${ }^{22}$ GRIFFITH, «From Aramaic to Arabic», págs. 11-31.

${ }^{23}$ Georg GRAF, Geschichte der christlichen-arabischen Literatur (Città del Vaticano: Biblioteca Apostolica Vaticana, 1944) vol. 1, pág. 104-108. Acerca de las traducciones árabes de la Biblia, véase Sidney H. GrifFith, The Bible in Arabic: The Scriptures of the 'People of the Book' in the Language of Islam (Princeton - Oxford: Princeton University Press, 2015).

${ }^{24}$ Acerca de la distinción entre las denominaciones 'siriaco' y 'arameo cristianopalestinense', véase Müller-Kessler y SoKoloff, A Corpus of Christian Palestinian Aramaic. Volume I, pág. 3, n. 1.

${ }^{25}$ Septuaginta Vetus Testamentum Graecum. I. Genesis, ed. John William WEVERS (Göttingen: Vandenhoeck \& Ruprecht, 1974) págs. 191-194.

${ }^{26}$ The Old Testament in Syriac according to the Peshitta Version, Part I. Fasc. 1. Preface. Genesis; Exodus. Edited by T[aeke] Jansma (Genesis) y M[arinus] D. Koster (Exodus) (Leiden: Brill, 1977).

${ }^{27}$ Biblia sacra iuxta Vulgatam versionem, ed. Bonifatius FISCHER et al., preparada por Roger GrYson (Stuttgart: Deutsche Bibelgesellschaft ,1994: reimp. de la ed. de 1969).

${ }^{28}$ Ténganse en cuenta los siguientes símbolos utilizados: $[\ldots]=$ vacat; $[\mathrm{xxx}]=$ elemento añadido en la traducción; $(\ldots)=$ texto omitido, $\mathrm{y}(\mathrm{xxx})=$ texto de la LXX y la Pešit țā ausente en ACP. 
A) Frag. ${ }^{r}$

\begin{tabular}{|c|c|}
\hline \multicolumn{2}{|c|}{$-19,1-$} \\
\hline 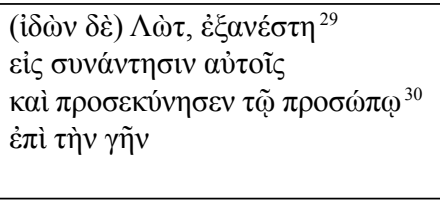 & 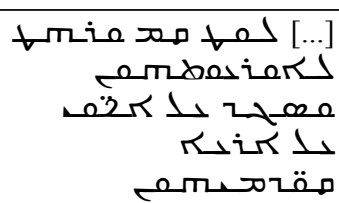 \\
\hline
\end{tabular}

Como se aprecia, la versión que ofrece ACP sigue literalmente el texto de la $\mathrm{LXX}^{31}$, aunque incluye una adición que no está presente en la versión griega $^{32}$ : el par adverbio + pron. suf. $3^{\mathrm{a}}$ p. m. pl. qūdmayhūn ('delante de ellos' $)^{33}$. Esta adición no se documenta en la versión siriaca de Pešit țtă, cuya traducción sigue de forma literal el texto hebreo masorético (THM):

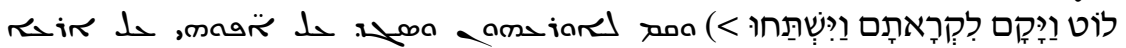

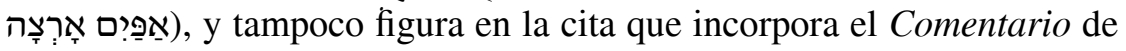

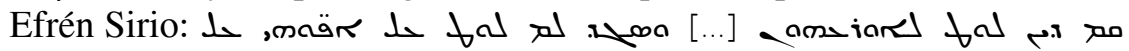
r Lir ('[...] Se levantó entonces Lot para recibirlos arrodillándose Lot rostro en tierra' ${ }^{34}$. El Comentario de İšū 'dad de Merv incluye únicamente una referencia mínima a este versículo: amziar bai ("Lot] corrió a su encuentro' $)^{35}$, que sirve para confirmar el uso generalizado del sustantivo

${ }^{29} C f$. Natalio Fernández Marcos y Ángel Sáenz-Badillos, Anotaciones críticas al texto griego del Génesis (Madrid-Barcelona: Consejo Superior de Investigaciones Científicas, 1972) pág. 50.

${ }^{30} C f$. Fernández Marcos y Sáenz-Badillos, Anotaciones críticas, pág. 91.

${ }^{31}$ Sobre el literalismo en las versions bíblicas, $c f$. James BARR, The Typology of Literalism in ancient biblical translations (Göttingen: Vandenhoeck \& Ruprecht, 1979).

${ }^{32}$ Cf. Septuaginta I. Genesis, ed. Wevers, pág. 191. Cf. además Takamitsu MuraoKa, A Syntax of Septuagint Greek (Leuven - Paris - Bristol, CT: Peeters, 2016) págs. 172, 504.

${ }^{33}$ Michael SoKoloff, A Dictionary of Christian Palestinian Aramaic (Leuven - Paris - Walpole, MA: Peeters, 2014) pág. 364b.

${ }^{34}$ Sancti Ephraem Syri in Genesim et in Exodum Comentarii, edidit R.-M. TONNEAU (Corpus Scriptorum Christianorum Orientalium 152, 153, Scriptores Syri, 71-72), 2 vols. (Leuven: Imprimerie orientaliste L. Durbecq, 1955) vol. I, pág. 77 (siriaco) vol. II, pág. 63 (latín).

${ }^{35}$ Commentaire d'Išo 'dad de Merv sur l'Ancien Testament I. Genèse, edité par J.M. Vosté et C. van den Eynde, traduit par Ceslas van den Eynde (Corpus Scriptorum Christianorum Orientalium 126, 156, Scriptores Syri, 67,75) (Leuven: Secrétariat du CorpusSCO, 1950) vol. I, pág. 162 (siriaco) vol. II, pág. 175 (francés). 
'ūra' (_ion 'encuentro') en las versiones siriacas. Pero en cambio, sí

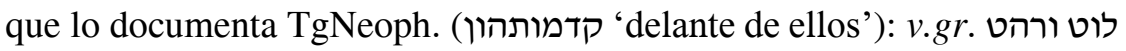
לקדמותהון ושאיל בשלמהון בנימוס ארעא.

Sin embargo, es interesante advertir que el ms. Sin. ar. 2 exhibe la misma adición (quddāmihimā, 'delante de ellos dos'): لوط فخرج يتلقاهما وسجد قدّامهما por lo que pudiera darse la casualidad de que esté relacionado con la versión ACP. Esta adición figura también en el Comentario anónimo de Diyarbakir, aunque debemos precisar que se trata propiamente de un comentario, no de una cita directa del texto bíblico: حم: ('Y [Lot] se inclinó ante ellos hasta el suelo')"

En cambio, la versión contenida en Sin. ar. 4 exhibe una traducción sintácticamente distinta en la que no figura la adición de ACP y Sin. ar.

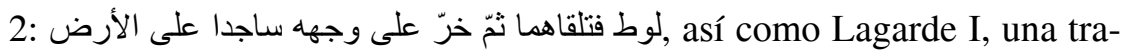
ducción de un original siriaco con catena على الأرض y lo mismo hay que decir de la versión atribuida a al-Hārit b. Sinān b. Sunbāt (ss. IX-X d.C.) ${ }^{38}$ contenida en Bodl. 258, que fue realizada a partir de la versión syro-hexaplar traducida por Pablo de Tellā'39 : لوط فقام نحو هما وخرّ على وجه الأرض

${ }^{36}$ Le Commentaire sur Genèse-Exode 9,32 du manuscrit (olim) Diyarbakir 22, edité et traduit par Lucas van RoMPay (Corpus Scriptorum Christianorum Orientalium 483-484, Scriptores Syri, 205-206) (Leuven: Peeters, 1986) I, pág. 81 (siriaco) II, pág. 104 (francés).

${ }^{37}$ Materialien zur Kritik und Geschichte des Pentateuchs, ed. Paul de Lagarde (Leipzig: B. G. Teubner, 1867) I, pág. 122.

${ }^{38}$ Sobre este autor, véase Joseph NASRALlaH, «Deux versions Melchites partielles de la Bible du IX et du Xe siècles», Oriens Christianus 64 (1980) págs. 206-210, e Histoire du mouvement littéraire dans l'église melqhite du Ve au XXe siècle. Contribution à l'étude de la littérature arabe chrétienne. Vol. II. Tome 2 (750-Xe s.) (Leuven: Peeters, 1988) págs. 187-188. Sobre la traducción, véanse Juan Pedro MoNFERRER-SALA, «Una traducción árabe del Pentateuco realizada sobre la versión syro-hexaplar de Pablo de Tellā», en

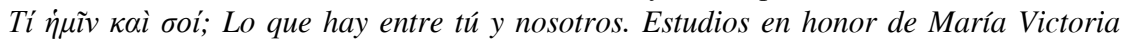
Spottorno (Córdoba: UCOPress, 2016) págs. 167-176, y «Una versión árabe cristiana del texto syro-hexaplar de Pablo de Tellā: Estudio filológico de la embajada al monarca de los amorreos (Nm 21,21-35)» (en prensa).

${ }^{39}$ Robert Holmes, Vetus Testamentum Graecum cum variis lectionibus (Oxford: Tipografía Clarendoniana, 1798) tomo I, págs. 50-55 (cap. IV) de la versión digital; Fridericus FIELD, Origenis hexaplorum quae supersunt; sive veterum interpretum graecorum in totum Vetus Testamentum fragmenta. Tomus I. Prolegomena: Genesis Esther (Oxford: Tipografía Clarendoniana, 1875) págs. 1xx-lxxi. 
Por su lado, en el comentario en árabe realizado por el nestoriano Ibn al-Țayyib (ss. X-XI) a partir de una traducción hecha sobre una versión siriaca nestoriana, junto con materiales exegéticos procedentes de autores siriacos ${ }^{40}$, tenemos la construcción sajada lahum frente a sajada

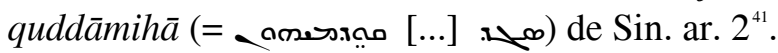

Finalmente, cabe indicar que en las versiones siriacas de los

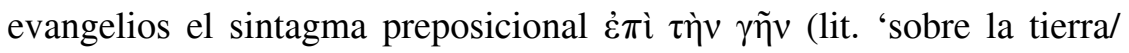

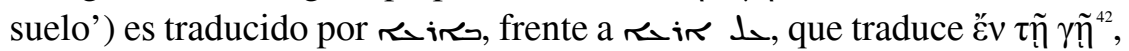
cuyo matiz diferencial estriba en la idea de movimiento implícita en la preposición 'al (ح) (ل)

\begin{tabular}{|c|c|}
\hline \multicolumn{2}{|l|}{$-19,2-$} \\
\hline 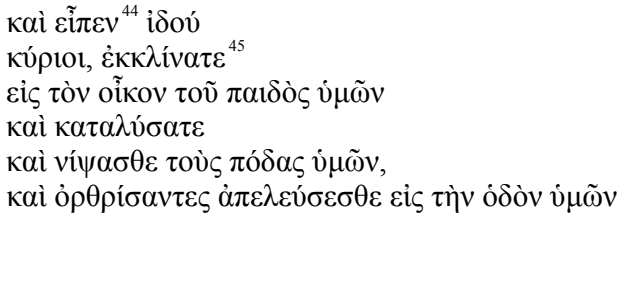 & 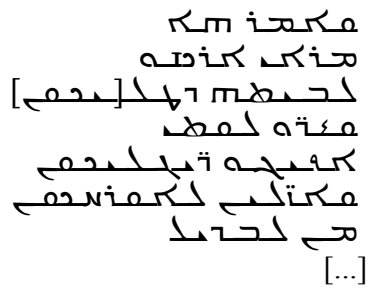 \\
\hline $\begin{array}{l}\text { 'Y dijo: «iMirad, señores míos! Os ofre } \\
\text { tomad aposento conmigo, lavad vuestr } \\
\text { continuad vuestro camino }\end{array}$ & $\begin{array}{l}\text { sa de vuestro siervo, } \\
\text { vantaos temprano y } \\
\text { e [...]' }\end{array}$ \\
\hline
\end{tabular}

También en este caso ACP sigue la versión de la LXX, con calcos léxi$\cos$ interesantes a nivel hermenéutico, como sucede con $\pi \alpha 1 \delta$ ò $(\pi \alpha \tilde{i} \varsigma)^{46}$,

${ }^{40}$ Véase al respecto Juan Pedro Monferrer-SALA, «The Lyre of Exegesis: Ibn alTayyib's analytical patterns of the account of the destruction of Sodom», en prensa.

${ }^{41}$ IBn AṬ-ȚAIYIB, Commentaire sur la Gènese, edición de Joannes Cornelis Josephus SANDERs, 2 vols. (Leuven: Sécrétariat du CorpusSCO, 1967) I, pág. 72 (árabe).

${ }^{42}$ Sobre la diferencia entre las preposiciones غ̇ंì y ع̌v, véase Archibald Thomas RoBERTSON, A Grammar of the Greek New Testament in the Light of Historical Research (New York: Hodder \& Stoughton, 1914) págs. 600-605 y 584-590, respectivamente.

${ }^{43}$ Jeffrey Paul Lyon, Syriac Gospel Translations: A Comparison of the Language and Translation Method Used in the Old Syriac, the Diatessaron, and the Peshitto (Leuven: Peeters, 1994) págs. 70-71.

${ }^{44} C f$. Fernández Marcos y Sáenz-Badillos, Anotaciones críticas, pág. 50.

${ }^{45} C f$. Fernández Marcos y Sáenz-Badillos, Anotaciones críticas, pág. 91.

${ }^{46}$ Henry St John Thackeray, A Grammar of the Old Testament in Greek according to the Septuagint. Vol. I (y único). Introduction, Orthography and Accidence (Cambridge: Cambridge University Press, 1909) págs. 7-8. Cf. Henry George Liddell y Robert ScotT, 
que es interpretado en ACP como taly $\left(\iota_{\downarrow}\right)$ con el significado básico de 'joven (de corta edad)', que también incluye la acepción de 'siervo' ('ěbed ${ }^{47}, c f$. Sin. ar. 2, Sin. ar. 4, Bodl 258, Lagarde I: ' $\left.a b d\right)^{48}$. Esta acepción de 'siervo' es la opción adoptada en la cita que incorpora el Comentario anónimo de Diyarbakir" : vuestro siervo' $)^{50}$. Esta cita tiene un enorme interés, porque no solo no se

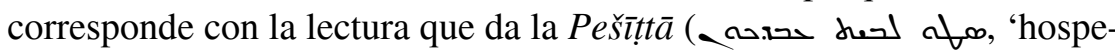

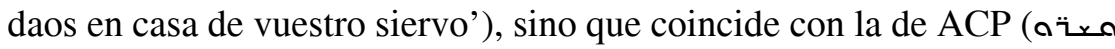

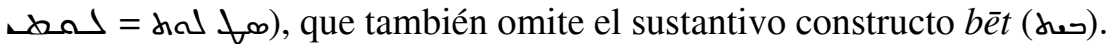

Pero, como en el caso anterior, lo más interesante es la inclusión de la

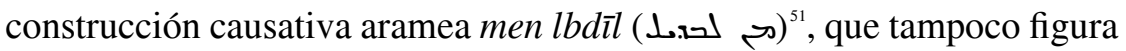
en la Pešịttā, en THM, ni en Sin. ar. 2, Sin. ar. 4 y Bodl. 258.

\begin{tabular}{|c|c|}
\hline \multicolumn{2}{|c|}{$-19,3-$} \\
\hline 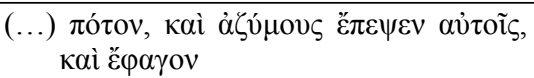 & 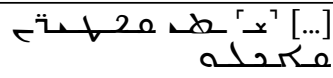 \\
\hline '[...] una bebida y panes & comieron' \\
\hline
\end{tabular}

Lamentablemente, este versículo nos ha llegado incompleto y apenas si nos permite realizar algún comentario sobre el mismo. Los tres términos que han sobrevivido indican que falta el verbo que rige los dos complementos directos šety y fațīīn ( fuera el mismo que recoge la Pešîttā, حجد. ('hacer'), que corresponde al

A Greek-English Lexicon (8th ed. rev., New York - Chicago: American Book Company 1897) pág. 1109b; cf. Evangelinus Apostolides SopHOcLEs, Greek Lexicon of the Roman and Byzantine Periods (Cambridge, MA - Leipzig: Harvard University Press - Otto Harrassowitz, 1914; reimp. Hildesheim - Zürich - New York: Georg Olms, 1992) pág. 830b.

${ }^{47}$ Sokoloff, A Dictionary of Christian Palestinian Aramaic, pág. 148b; Robert PAYNE Sмiтн, Thesaurus syriacus. Collegerunt Stephanus M. Quatremere et al., 2 vols. (Oxford: Tipografía Clarendoniana 1879, 1901) vol. I, col. 1472, cf. Abraham TAL, A Dictionary of Samaritan Aramaic, 2 vols. (Boston - Köln: Brill, 2000) vol. I, pág. 311b, s.v. טלי

${ }^{48}$ Materialien, ed. LAGARDE, pág. 122.

${ }^{49}$ Le Commentaire Diyarbakir 22, ed. VAN Rompay, I, pág. 81 (siriaco) II, pág. 104.

${ }^{50}$ Lit. 'Bajad en vuestro siervo'.

${ }^{51}$ Sokoloff, A Dictionary of Christian Palestinian Aramaic, pág. 192a-b; PAYNE SMITH, Thesaurus syriacus I, col. 451; cf. TAL, A Dictionary of Samaritan Aramaic, I, págs. 81a-82a.

${ }^{52}$ Sobre los sustantivos šety y fațīiñn, véase SoKoloff, A Dictionary of Christian Palestinian Aramaic, págs. 447a y 327a, respectivamente. 


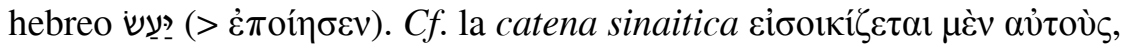

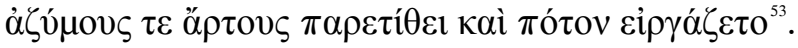

La versión árabe que ofrece Sin. ar. 2 es interesante porque no sigue un texto en concreto, sino que parece ser el resultado de consultar varios textos entre los que ha prevalecido la versión de la LXX sobre la Pešit țtā a juzgar por el resultado final: فصنع لهما تكأ وخبز لهما فطير ا فأكلا ('y les hizo a ambos un festín, les amasó pan ácimo y comieron'). Aunque con un cambio en el orden de la palabras, Ibn al-Țayyib coincide con Sin. ar. 2 en la oración wa-habaza al-fațī lahum ('y les amasó pan acimo') ', muy cercana a la cita que recoge el Comentario de Ǐšū'dad de Merv: and ('pan ácimo coció para ellos')"

Sin. ar. 4, en cambio, ofrece una traducción distinta: فأعد لهما طعاما وهيّ لهonaوهيّأ لهما مشربا وخبز لهما فطبرا :وon'), como también sucede en Bodl. 258 فاكلا ('y les preparó bebida, les amasó pan ácimo y comieron'), cuya versión es idéntica a la de Lagarde I, con excepción del segundo CI lahumā y la marca de indeterminación del segundo CD, ausente en Bodl. 258: .

\begin{tabular}{|c|c|}
\hline \multicolumn{2}{|c|}{$-19,4-$} \\
\hline 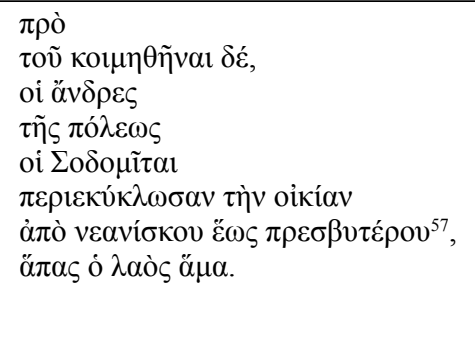 & 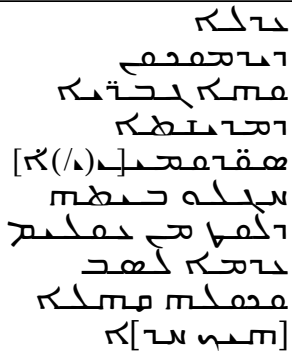 \\
\hline
\end{tabular}

${ }^{53}$ Catenae graecae in Genesim et in Exodum, edita a Françoise PetrT (Turnout Leuven: Brepols - Leuven University Press, 1977) pág. 99, núm. 97.

${ }^{54}$ Iвn AṬ-ȚAIYIB, Commentaire sur la Gènese I, pág. 72 (árabe).

${ }^{55}$ Commentaire d'Išo 'dad de Merv, ed. vosté et van den Eynde I, pág. 162 (siriaco) II, pág. 176 (francés).

${ }^{56}$ Materialien, ed. Lagarde, I, págs. 122 y 123 (catena).

${ }^{57} C f$. Fernández Marcos y SÁEnz-Badillos, Anotaciones críticas, pág. 103. 
El versículo cuatro nos proporciona una variante en la modalidad de adición, se trata del antropónimo Lūṭ $(\downarrow-\downarrow){ }^{58}$ que no figura en la versión de la $\mathrm{LXX}^{59}$. Tampoco Sin. ar. 2, Sin. ar. 4 y Bodl. 258, como asimismo sucede con la versión de la Pešit ță, exhiben el nombre propio. La dependencia de ACP de la LXX se advierte en la correspondencia léxica tĩ $\pi$ ó $\lambda \varepsilon \omega \varsigma=$ గ مس ('la ciudad'), que en Bodl. 258 y Lagarde I adquiere naturaleza expansiva: madīnat Sadūm (مدينة سدوم). Sin embargo, la Pešìt țā y las otras

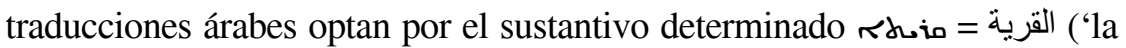
aldea'), la misma opción elegida por los targûmîm Lagarde II, que recoge una versión árabe copta de la traducción de Sa adyah Gaón sigue esta misma tradición con la adición del topónimo (قرية سدوم)

\begin{tabular}{|c|c|}
\hline \multicolumn{2}{|c|}{$-19,5-$} \\
\hline 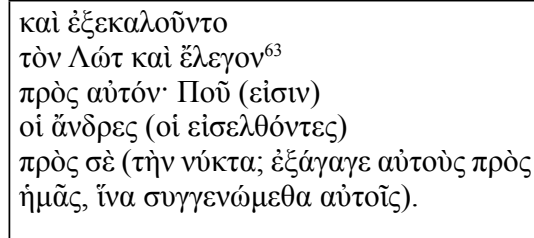 & 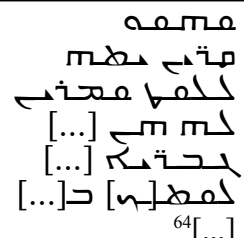 \\
\hline
\end{tabular}

También en este caso, el carácter fragmentario en el que nos ha llegado el texto no nos permite realizar comentarios, salvo recalcar que el texto conservado es una traducción literal de la LXX, si bien no muy alejado de la versión de la Pešĭt tta $\bar{a}^{65}$ :

${ }^{58}$ Cf. Le Commentaire Diyarbakir 22, ed. VAN Rompay I, pág. 81 (siriaco) II, pág. 105 (francés).

${ }^{59}$ Cf. Septuaginta I. Genesis, ed. Wevers, pág. 192.

${ }^{60}$ Materialien, ed. LaGarde, I, pág. 122.

${ }^{61}$ The Bible in Aramaic, based on manuscripts and printed texts, edited by Alexander SPERBER (Leiden - Boston: Brill, 2004) pág. 26.

${ }^{62}$ Materialien, ed. Lagarde, II, pág. 18.

${ }^{63}$ Cf. Fernández Marcos y SÁenz-Badillos, Anotaciones críticas, pág. 103.

${ }^{64}$ El sintagma blelyā (حك), la misma lectio que recoge la Pešit țā, es interpretación

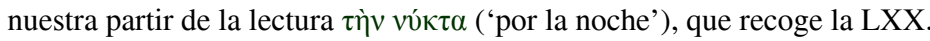

${ }^{65}$ Cf. Sancti Ephraem Syri in Genesim et in Exodum Comentarii, ed. R.-M. Tonneau,

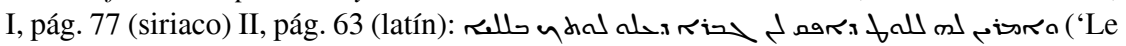
decían a Lot: «¿Dónde están los hombres que vinieron a ti por la tarde?»’). 


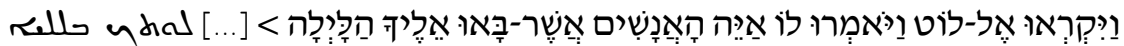

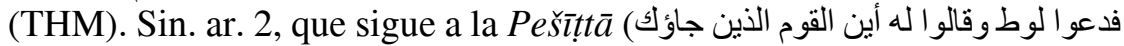
(لليلة), ofrece una versión muy cercana a la versión árabe hexaplar de Bodl.

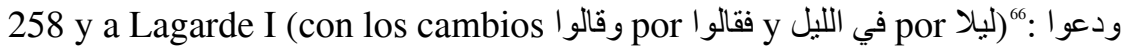

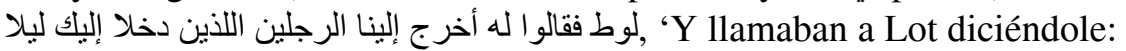
Sácanos a los dos hombres que han venido a ti por la tarde'. Sin. ar. 4 pre-

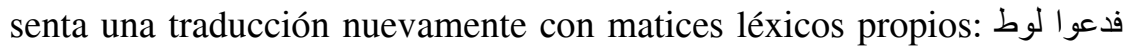

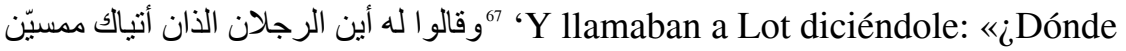
están los dos hombres que han venido a ti de tardecita?»'.

B) Frag. $I^{v}$

\begin{tabular}{|c|c|}
\hline \multicolumn{2}{|c|}{$-19,7-$} \\
\hline 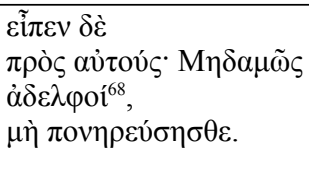 & 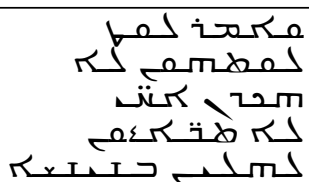 \\
\hline 'Y Lot les dijo: «I & obréis mal a estos \\
\hline
\end{tabular}

De nuevo, como en el versículo 4, ACP incluye la adición del nombre propio Lūt ( $\downarrow$ )), que no figura en la LXX'. El adverbio $\mu \eta \delta \alpha \mu \tilde{\omega} \varsigma$ ('de

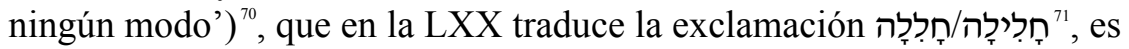

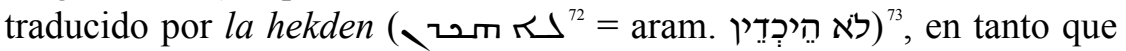
la Pešit țā omite la construcción adverbial, como asimismo sucede con Sin ar. 2: فقال لهم لوط لا تسوا إليّ يأخوني ('y les dijo Lot: «iNo me hagáis mal, hermanos míos!»') y los commentaria syriaca.

\footnotetext{
${ }^{66}$ Materialien, ed. LAGARDE, I, pág. 122.

67 sمسيّن es una hipocorrección del árabe medio por من مسيّان.

${ }^{68}$ Cf. Fernández Marcos y Sáenz-Badillos, Anotaciones críticas, pág. 103.

${ }^{69}$ Cf. Septuaginta I. Genesis, ed. Wevers, pág. 193.

${ }^{70}$ MuraoKa, A Syntax of Septuagint Greek, pág. 479.

${ }^{71}$ Francis Brown, Samuel R. Driver y Charles A. Briggs, A Hebrew and English Lexicon of the Old Testament, with an Appendix containing the Biblical Aramaic (Boston - New York: Houghton Mifflin \& Co., 1891) pág. 321a.

${ }^{72}$ Sokoloff, A Dictionary of Christian Palestinian Aramaic, pág. 101b.

${ }^{73}$ Marcus JASTROw, A Dictionary of the Targumim, the Talmud Babli and Yerushalmi, and the Midrashic Literature, 2 vols. (London - New York: Luzac \& Co. - G. P. Putnam's Sons, 1903) I, pág. 345a.
} 
A su vez, el vocativo $\alpha \dot{\alpha} \varepsilon \lambda \varphi$ í $^{74}$ es traducido en ACP con un pr. pos.

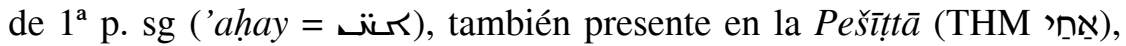

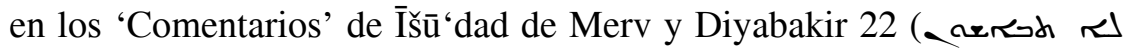
sữ ‘¡no hagáis mal, hermanos míos!') 75, así como también en Sin. ar. 2, Bodl. 258 y Lagarde I y II ${ }^{76}$. Sin embargo, Sin. ar. 4 exhibe otra lectura en la que el pronombre posesivo no figura: فقال لهم لوط لا تسو ا بي ياإخوة (y les dijo Lot: «¡No me hagáis mal, hermanos!»’). Un último rasgo digno de interés es que Sin. ar. 2 y 4 complementan la construcción verbal negativa

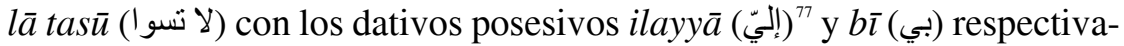
mente, en tanto que la LXX y ACP recogen las construcciones verbales

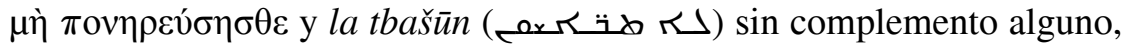
como asimismo sucede en Bodl. 258.

Pero lo más interesante es que ACP aporta una variante sintáctica gra-

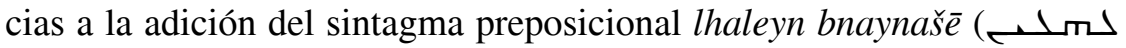
حــــ 'a estos hombres'), que no figura en la $\mathrm{LXX}^{78}$, la Pešițtiā, los commentaria syriaca ni en las traducciones árabes.

\begin{tabular}{|c|c|}
\hline \multicolumn{2}{|c|}{$-19,8-$} \\
\hline 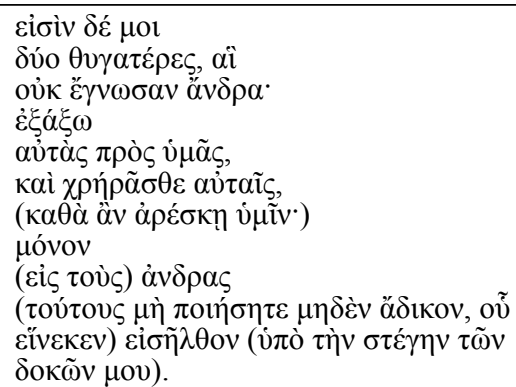 & 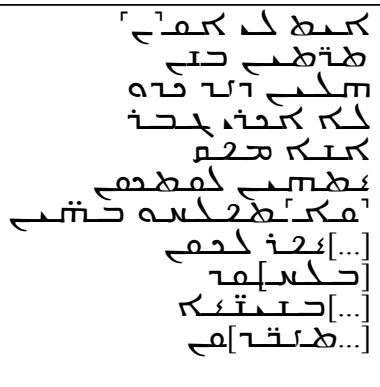 \\
\hline
\end{tabular}

En este versículo llaman la atención dos rasgos léxicos: por un lado

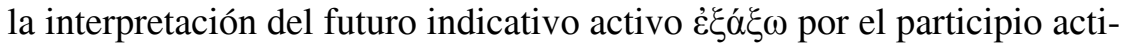

${ }^{74}$ MuraoKa, A Syntax of Septuagint Greek, pág. 479.

${ }^{75}$ Commentaire d'Išo 'dad de Merv, ed. Vosté et VAN DEN Eynde, I, pág. 162 (siriaco) II, pág. 176 (francés); Le Commentaire Diyarbakir 22, ed. VAN RomPay I, pág. 81 (siriaco) II, pág. 104 (francés).

${ }^{76}$ Materialien, ed. LAGARde, I, pág. 122 y II, pág. 18.

${ }^{77}$ Así también Materialien, ed. LAGARDE, II, pág. 18.

${ }^{78}$ Cf. Septuaginta I. Genesis, ed. WeVERs, pág. 193. 
vo mapeq $\left({ }^{2}-\right)^{79}$, que las versiones árabes traducen, respectivamente, con el imperfectivo ahruju (Sin. ar. 2, Sin. ar. 4 y Lagarde I ${ }^{80}$; Pešīṭta:

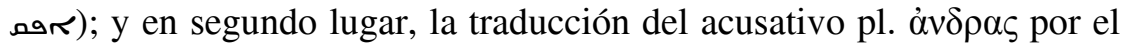
pl. bnaynašā en lugar de recurrir, en consonancia con la opción tomada en la primera oración (őv $\delta \rho \alpha^{81}=\dot{ح} ح-$ ), al sustantivo pl. gabrēe, o en su defecto a naš $\bar{e}^{82}$. Todo indica que se trata de una estrategia consistente en evitar la repetición, recurriendo de este modo a otra opción léxica, el compuesto bnaynašă, pl. de bar našā ('hijo de hombre') ${ }^{83}$ y equivalente del también pl. de este bnay našă.

Es interesante que la versión contenida en Sin. ar. 2, que en la primera

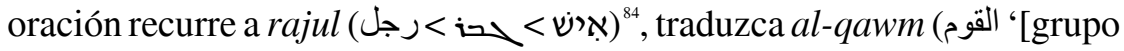
de] gente' $)^{85}$, coincidiendo de este modo con en el matiz generalista que ofrece ACP con bnaynašā; este interés es mayor, si cabe, porque la Pešit țtā usa la misma palabra en los dos casos. Lo mismo acontece en Sin. ar. 4, que recurre al mismo sustantivo en ambos casos, el primero en singular indeterminado (رجل) y el segundo en dual determinado (الرجلين).

Pero más interesante es, si cabe, la estrategia léxica adoptada por Bodl. 258 y Lagarde I ${ }^{86}$, que en el primer caso traduce el generalista bašar (بشر 'hombre; humanidad'), mientras que para el segundo caso recurre

${ }^{79} C f$. la traducción de la partícula $\ddot{\varepsilon} \xi \omega$ por sas en las versiones del NT, $c f$. Peter J. Williams, Early Syriac Translation Technique and the textual Criticism of the Greek Gospels (Piscataway, NJ: Gorgias Press, 2004) págs. 162-163.

${ }^{80}$ Materialien, ed. LaGarde, I, pág. 122.

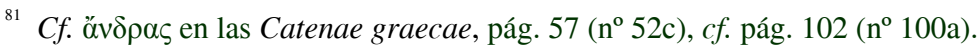

${ }^{82}$ En el caso de las traducciones del NT contamos con las equivalencias en singular

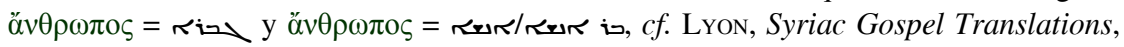
pág. 155.

${ }^{83}$ Geza Vermes, «The Use of בר נשא/בר נש in Jewish Aramaic», en An Aramaic Approach to the Gospels and Acts, ed. Matthew BLACK (Oxford: Clarendon Press, 1971; reimp. de la ed. 1946) págs. 310-330.

${ }^{84} \mathrm{Vg}$. habeo duas filias quae nondum cognoverunt virum; cf. Qu. hebr. 29,12: ecce duae filiae meae, quae non cognouerunt uirum, apud S. Hieronymi Presbyteri Opera. Pars I. Opera exegetica 1: Hebraicae qvaestiones in libro Geneseos, liber interpretationis hebraicorvm nominvm, commentarioli in Psalmos, commentarivs in Ecclesiasten, edición de Paulus Antin (Turnout: Brepols, 1959) pág. 23, 1s. 9-10.

${ }^{85}$ Así también Materialien, ed. Lagarde, II, pág. 18.

${ }^{86}$ Materialien, ed. LAGARDE, I, pág. 122. 
a al-rajulāni (الرجلان 'los dos hombres'). Todo indica que el cambio de sustantivos obedece a un deseo obvio de distinguir entre lo general (indefinido) y lo particular (definido).

El Comentario de $\overline{\text { Išù }}$ 'dad de Merv incluye la cita, que supone una variante con respecto a ACP y LXX, cuya versión recoge en una glosa

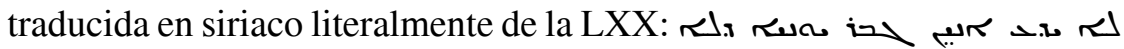
("no las ha conocido hombre; el Griego (i.e. LXX): que no han

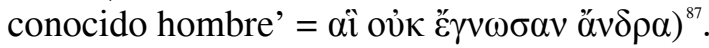

Por último, debemos añadir dos comentarios más: en primer lugar, la equivalencia adverbial hóvov = حكـ ('solo') que exhibe ACP, ade-

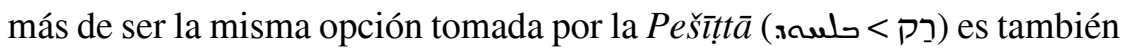
habitual en las traducciones siriacas del $\mathrm{NT}^{88}$. Y en segundo, resaltar la variante por adición que incluye $\mathrm{ACP}$ con respecto a la $\mathrm{LXX}^{89}$ mediante la inclusión de la locución adverbial 'ad kadū ( en la Pešițtā, los commentaria syriaca y las traducciones árabes.

\begin{tabular}{|c|c|}
\hline \multicolumn{2}{|c|}{$-19,9-$} \\
\hline 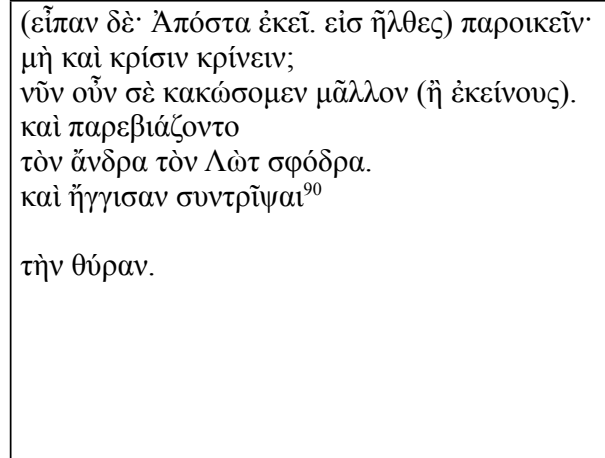 & 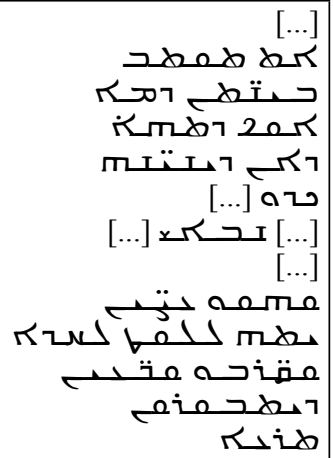 \\
\hline
\end{tabular}

${ }^{87}$ Commentaire d'Išo ‘dad de Merv, ed. Vosté et van DEN Eynde I, pág. 163 (siriaco) II, pág. 176 (francés).

${ }^{88}$ Cf. Williams, Early Syriac Translation Technique, págs. 168-169.

${ }^{89}$ Cf. Septuaginta I. Genesis, ed. WeVERs, pág. 193.

${ }^{90}$ Para esta acentuación de la iota, véase Peter WALTERS, The Text of the Septuagint: Its Corruptions and Emmendations. Edited by D. W. Gooding (New York: Cambridge University Press, 1973; reimp. 2009) pág. 96.

${ }^{91}$ Lit. 'emitir su juicio'. 
En este caso cabe destacar la traducción del acusativo sing. кpíoıv ('juicio') $)^{92}$ por dinyeh (mتــ 7$)^{93}$, que incorpora el sufijo pronominal de $3^{\text {a }}$ p. masc. ('su juicio') ausente en el texto de la $\mathrm{LXX}^{94}$. Sin. ar. 2 traduce la lectio de la Pešit țta ('juicio’) por al-qadāa (القضاء) con idéntico significado, mientras que Bodl. 258 opta por una traducción literal de la versión syro-hexaplar y por ello muy cercana a la LXX, igual que Lagar-

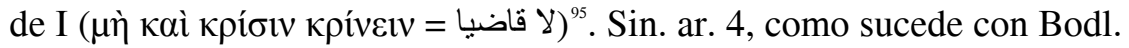
258, omite el sustantivo por resultarle expletivo y restringe la traducción al verbo yаһ̆kuти (يحكم, 'enjuiciar')

\begin{tabular}{|c|c|}
\hline \multicolumn{2}{|c|}{$-19,10-$} \\
\hline 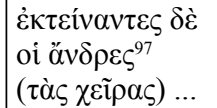 & مـحستحتح \\
\hline
\end{tabular}

Las tres palabras que nos han llegado de este décimo versículo no nos permiten emitir ningún juicio particular acerca de la traducción, aunque con la adaptación correspondiente a las reglas gramaticales del ACP, esta representa una traducción literal de la LXX con las equivalencias que indicamos:

\begin{tabular}{|c|c|c|c|c|c|c|c|}
\hline LXX & $\mathrm{ACP}$ & Pešitịtā & Sin. ar. 2 & Sin. ar. 4 & Bodl. 258 & Lagarde I & Lagarde II \\
\hline$\dot{\varepsilon} \kappa \tau \varepsilon i ́ v \alpha \nu \tau \varepsilon \zeta$ & 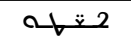 & of ear & بسطا & مدّ & مدّ & مدّ & مدّ \\
\hline$\delta \dot{\varepsilon}$ & 2 & - & - & - & - & - & - \\
\hline oi $\alpha \ddot{\alpha} v \delta \rho \varepsilon \varsigma$ & K几̈Z & rin & - & الرجلان & الرجلان & الرجلان & الملاكان \\
\hline
\end{tabular}

Como se advierte, el rasgo discriminativo lo representa la partícula copulativa griega $\delta \grave{\varepsilon}$ ('luego'), traducida en ACP por su equivalente aramea

\footnotetext{
${ }^{92}$ Para la construcción con acusativo interno como resultado de una figura etymologica

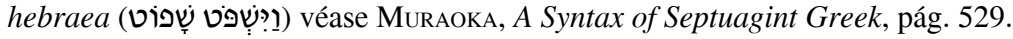

${ }^{93}$ Soкоloff, A Dictionary of Christian Palestinian Aramaic, pág. 86b.

${ }^{94}$ Cf. Septuaginta I. Genesis, ed. Wevers, pág. 193.

${ }^{95}$ Materialien, ed. LaGarde, I, pág. 123. Lamentablemente una gran porción del libro del Gn en la versión syro-hexaplar, incluido el pasaje objeto de estudio, no ha llegado hasta nosotros en los manuscritos fragmentarios conservados, véanse Paul DE LAGARDE, Bibliothecae Syriacae quae ad philologiam sacram pertinent (Göttingen: Dietrich, 1892) y Arthur Vööвus, The Pentateuch in the Version of the Syro-Hexapla (Leuven: Secrétariat du CorpusSCO, 1975).

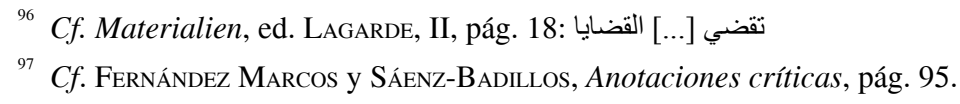


ken precedida de la prep. enclítica $b$ - (حح), que se halla ausente en el resto de versiones que dependen de la Pešit țtā o de otras Vorlagen donde esta partícula no aparece porque su original, como en el caso del THM, no la contiene.

Las versiones árabes llaman la atención por dos singularidades: la primera porque Sin. ar. 2 omite el sujeto de la oración (الرجلان/ الرجال

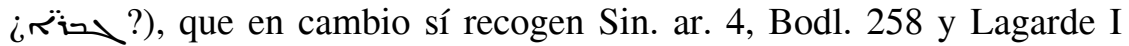
(الرجلان); y la segunda, de carácter léxico, dado que gabrayē tiene la acepción de 'afeminado', que Sin. ar. 4 y Bodl. 258 no captan con la forma dual al-rajulāni ('dos hombres'). Probablemente este sentido peyorativo de gabrayē (cf. Pešìtt tà gabrē) sea la explicación de la opción tomada por Sin. ar. 2 de no traducir dicho término. Obviamente la traducción al-malākāni ('los dos ángeles') de Sa'adyah (Lagarde II) es el resultado de la exégesis del Gaón ( $c f$. Gn 19,1).

\section{ACP y PEŠİTTĀ: COINCIDENCIAS Y DIVERGENCIAS}

Las divergencias que exhibe ACP con respecto a la LXX, así como algunas de las estrategias por las que optó su traductor pueden obedecer a interferencias procedentes de otros textos, principalmente del texto siriaco de la Pešit țtă, que circulaba con anterioridad a ACP, concretamente en un momento determinado entre los I y III d.C. ${ }^{99}$.

Es cierto que la Pešit țā exhibe muchos paralelos tanto con la LXX como con los targûmîm, con lo que en determinados casos puede depender de una u otras versiones ${ }^{100}$. Ahora bien, esta dependencia, obviamente, no invalida que en determinados casos el texto siriaco de la Pešit ța haya

${ }^{98}$ Materialien, ed. LaGARDE, I, pág. 123.

${ }^{99}$ Michael P. Weitzman, «From Judaism to Christianity: The Syriac Version of the Hebrew Bible», en The Jews among Pagans and Christians in the Roman Empire, eds. Judith Lieu, John North y Tessa Rajak (London: Routledge, 1992) págs. 147-173; $c f$. Michael P. Weitzman, The Syriac Version of the Old Testament (Cambridge: Cambridge University Press, 1999) págs. 206-262.

${ }^{100}$ Michael P. Weitzman, «Peshitta, Septuagint and Targum», en VI Symposium Syriacum 1992, edición de René Lavenant (Roma: Pontificio Istituto Orientale, 1994) págs. 51-84, y Petra Verwiss, «The Septuagint in the Peshitta and Syro-Hexapla Translations of Amos 1:3-2:16», Bulletin of the International Organization for Septuagint and Cognate Studies 38 (2005) págs. 25-40. 
podido influir o interferir en ACP en la elección lexical e incluso en la sintaxis. A continuación analizamos verso a verso la posible relación que se haya podido dar entre ACP y la Pešìtt

\begin{tabular}{|c|c|c|}
\hline Pešìt țtà & $\mathrm{ACP}$ & \\
\hline 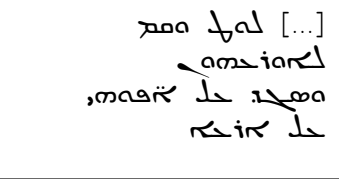 & 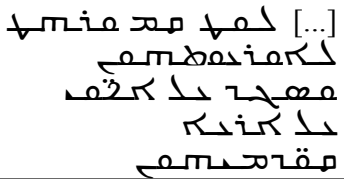 & 1 \\
\hline \multicolumn{3}{|c|}{. [....] : TgNeoph. לוט ורהט לקדמותהון ושאיל בשלמהון בנימוס ארעא } \\
\hline
\end{tabular}

Aun cuando ACP traduce a la LXX, exceptuando la adición مقحסــم (también presente en TgNeoph.), sin embargo las opciones léxicas adoptadas por aquel coinciden plenamente con las de la Pešit țtâ, salvo por los mínimos aspectos gramaticales que indicamos, que en nada afectan al sentido:

\begin{tabular}{|c|c|}
\hline Pešìtttā & $\mathrm{ACP}$ \\
\hline ممة - مסק & مـ2 \\
\hline amviand & 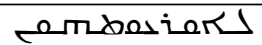 \\
\hline 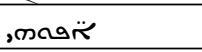 & תـR \\
\hline
\end{tabular}

\begin{tabular}{|c|c|c|}
\hline Pešìtttā & $\mathrm{ACP}$ & \\
\hline 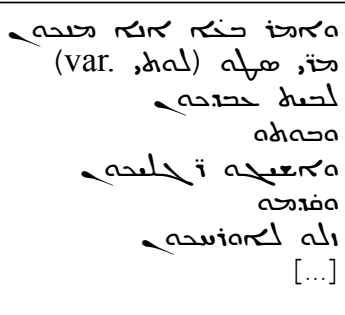 & 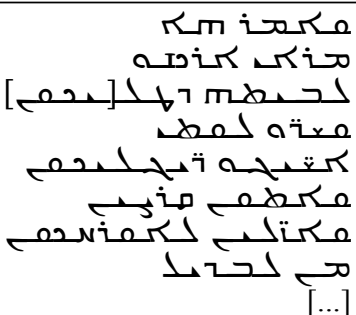 & 2 \\
\hline
\end{tabular}

El cotejo de las dos versiones nos permite constatar equivalencias léxicas entre ACP y la versión de la Pešịt țā: v.gr. .

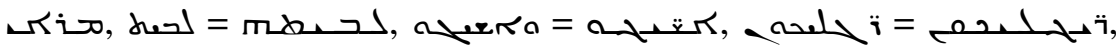

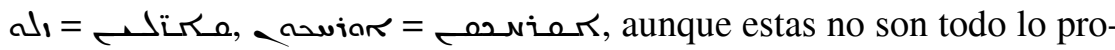
ductivas que cabría desear, pues además de las variantes gramaticales que se dan en varias de ellas, los términos representan opciones léxicas estándar en siriaco. En consecuencia creemos que ACP no ha optado por seguir el estilo de la Peš̌t țta en este caso. 


\begin{tabular}{|c|c|c|}
\hline Pešìțtā & ACP & \\
\hline 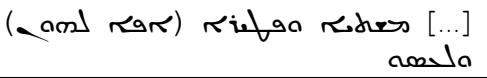 & 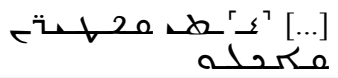 & 3 \\
\hline
\end{tabular}

Aun cuando el texto que nos ha llegado es muy breve y en consecuencia no permite una labor analítica en detalle, sin embargo las opciones léxicas nos indican una falta de correspondencia entre ambas versiones:

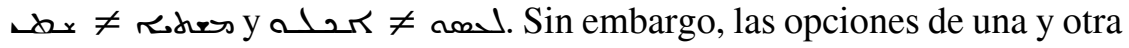
traducción coinciden alternativamente con las de los targûmîm, mientras

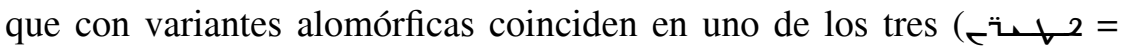
פטירי / פטיר (TgPs.J.) פטיר (TgNeoph.):

\begin{tabular}{|c|c|}
\hline $\mathrm{ACP}$ & Pešitțā \\
\hline$\leq x \neq$ & 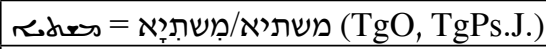 \\
\hline אַכַלוּ = אـ $(\mathrm{TgO})$ & $\neq$ and \\
\hline
\end{tabular}

\begin{tabular}{|c|c|c|}
\hline Pešìt ța & $\mathrm{ACP}$ & \\
\hline 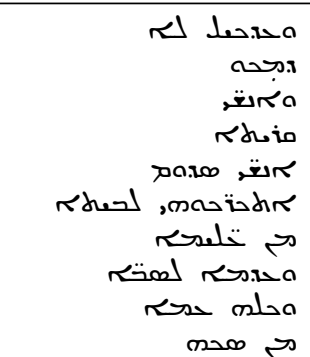 & 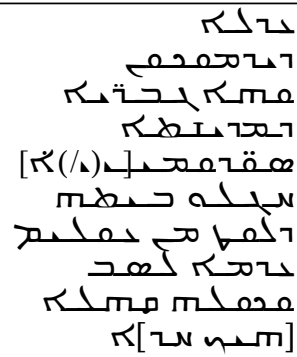 & 4 \\
\hline
\end{tabular}

Las versiones de ACP y Pešit țā responden a dos estrategias de traducción distintas, aunque se da una coincidencia plena en el sintagma

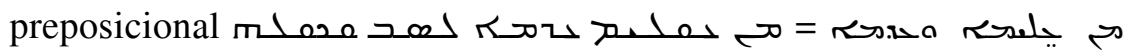
لهيح محله ('desde el más joven hasta el más viejo'), que coincide, por lo demás, con la versión que ofrece TgNeoph.: מן עולימיהון ועד סביהון.

\begin{tabular}{|c|c|c|}
\hline Pešìt țta & $\mathrm{ACP}$ & \\
\hline 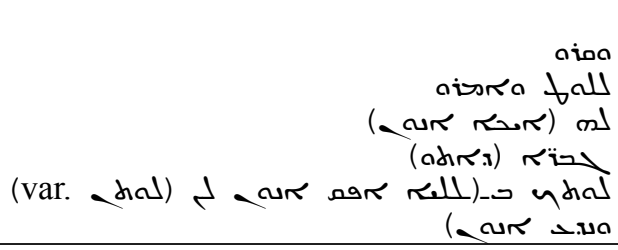 & 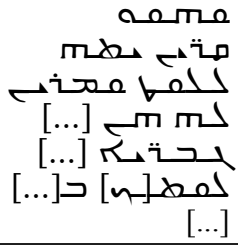 & 5 \\
\hline
\end{tabular}


Pese a que ACP exhibe una traducción estilísticamente más expansiva que la Pešit țā en este versículo fragmentario, sin embargo las coincidencias son evidentes en el texto conservado con las diferencias gramaticales lógicas entre un registro culto (Peš̄ țtā) y otro dialectal (ACP). La versión

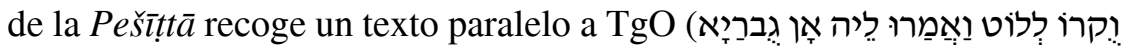

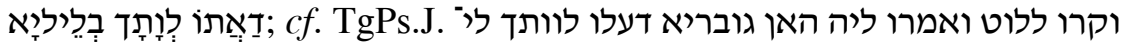

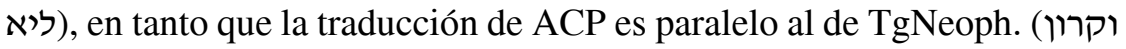
(ללוט ואמרין ליה אן (אנון) גובריא (די אתון) לוותך בליליא.

\begin{tabular}{|c|c|c|}
\hline Pešịtttā & $\mathrm{ACP}$ & \\
\hline 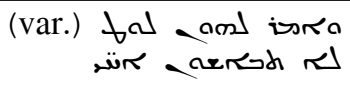 & 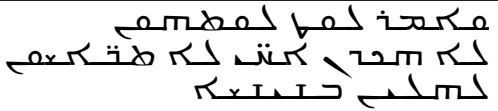 & 7 \\
\hline
\end{tabular}

Las diferencias entre ACP y la Pešịttā son tres: una de naturaleza sintáctica, orden de las palabras distinto, la ausencia de la construcción ad-

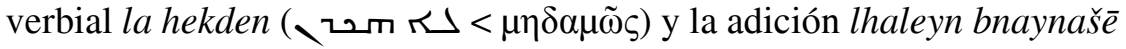

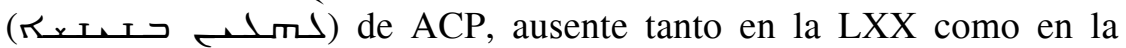
Pešițtā. Pero lo más interesante, independientemente de estas diferencias, que no es el resultado de una opción estilística frente a la Pešit țtā, sino el producto de una traducción ad pedem litterae de la LXX, es que la adición del antropónimo Lot en ACP también está documentado en una variante manuscrita de la Pešịttā y en el fragmento del TgNeoph. de la Vaticana (FTV): v.gr. ואמר להון לוט.

\begin{tabular}{|c|c|c|}
\hline Pešìttāa & $\mathrm{ACP}$ & \\
\hline 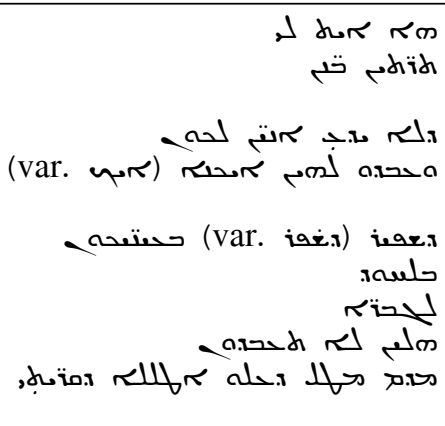 & 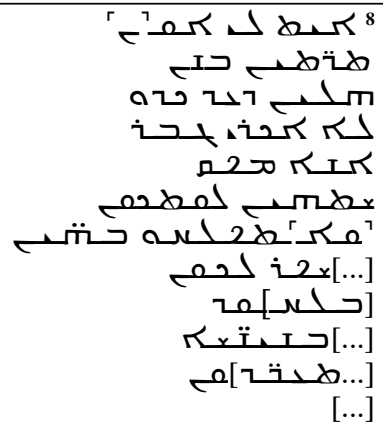 & 8 \\
\hline
\end{tabular}

En este versículo, en el que las coincidencias entre ACP y la Pešịttā

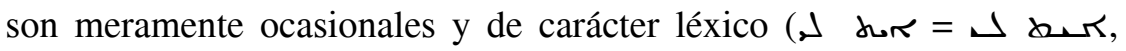




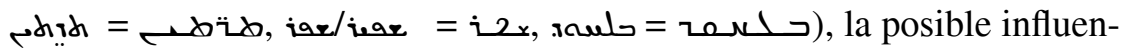
cia de la Pešițtā en ACP creemos que queda prácticamente descartada.

\begin{tabular}{|c|c|c|}
\hline Peš̄ịttā & $\mathrm{ACP}$ & \\
\hline 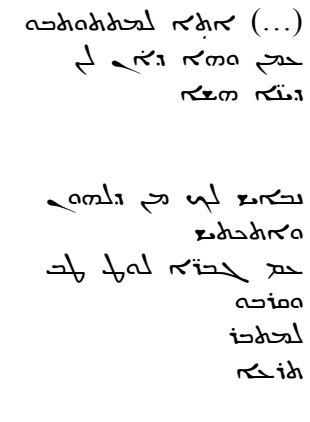 & 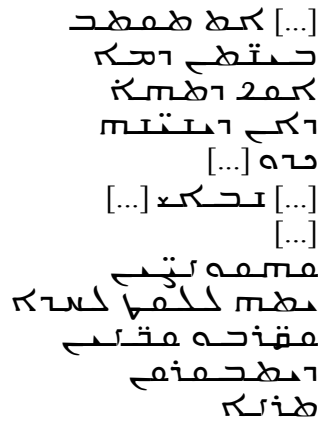 & 9 \\
\hline
\end{tabular}

También en este caso, pese a las mínimas coincidencias léxicas (همس

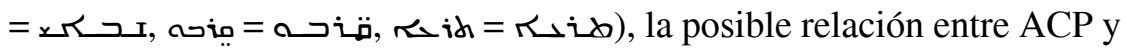
la Peš̃

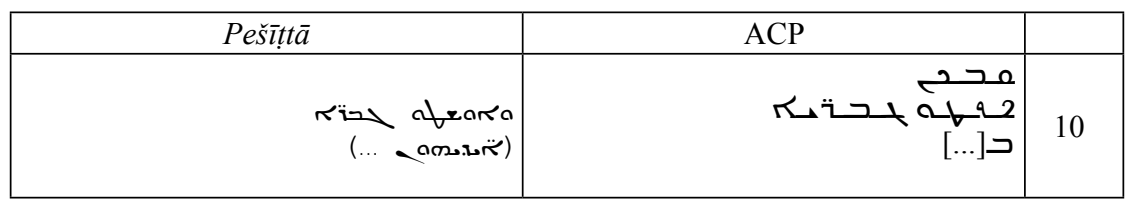

En este último versículo, excesivamente fragmentario, tampoco apreciamos ninguna dependencia de ACP con la Pešițtā. Adviértase, por lo

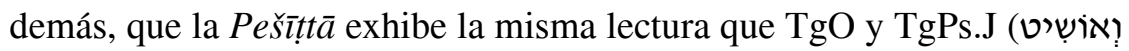
(וּ גְברָיָא exceptuando la conjunción $(\mathrm{I})$ y el complemento directo que en ACP es expresado mediante un sintagma preposicional introducido con preposición preclítica $b$-.

\section{Conclusiones}

La versión contenida en los dos fragmentos ACP que hemos analizado muestra una clara dependencia con un texto griego de la familia de la LXX. Esta dependencia se advierte de modo inequívoco en la co-

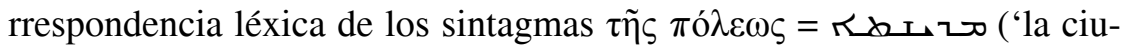
dad'), que Bodl. 258 y Lagarde I expanden en madīnat Sadūm (مدينة سدوم, 
'la ciudad de Sodoma'). Sin embargo, la Pešịt tā y las otras traducciones árabes optan por otra posibilidad léxica: القرية = منبط ('la aldea'), en la misma línea que los targûmîm:קרתא, que obviamente nos sitúan en otra tradición textual.

La traducción de ACP, sin embargo, exhibe algunas diferencias con respecto a la LXX, como por ejemplo la variante sintáctica lhaleyn

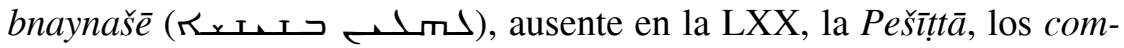
mentaria syriaca y las versiones árabes. Sin embargo, el rasgo más recurrente que presenta ACP es el de la adición, concretamente en los casos que indicamos:

\begin{tabular}{|c|c|}
\hline 19,1 & 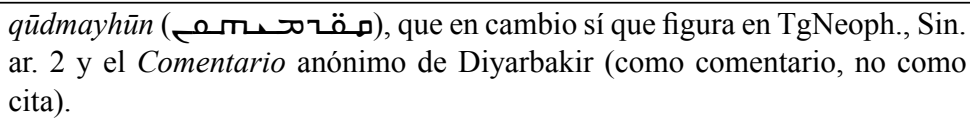 \\
\hline 19,2 & 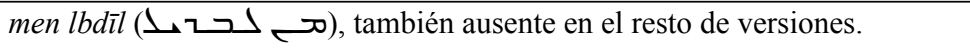 \\
\hline $19,4.7$ & Lūt (لمه $\mid ح)$, también ausente en las versiones restantes. \\
\hline 19,8 & 'ad kad̄u (ดح حר), ausente también en el resto de versiones. \\
\hline
\end{tabular}

Aunque de menor entidad, contamos con dos adiciones más en ACP frente a la LXX, en forma de añadidos pronominales:

\begin{tabular}{|c|c|}
\hline 19,7 & 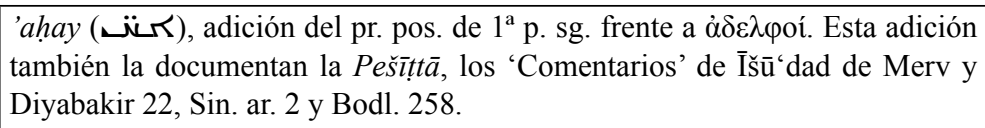 \\
\hline 19 & del sufijo pronominal de $3^{a}$ p. masc. \\
\hline
\end{tabular}

Por otro lado, es cierto que las coincidencias que se dan entre ACP y la Pešt țtā no son muchas, pero sin embargo en los veinte versículos que indicamos se advierten opciones léxicas idénticas o semejantes adoptadas por ACP y la Peši țtā:

\begin{tabular}{|c|c|c|c|}
\hline Versículos & Pešìt țta & $\mathrm{ACP}$ & Targûmîm \\
\hline 1 & ممج & סـק & \\
\hline 1 & مian & אـمـاند & \\
\hline 1 & אمרחות, & 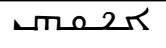 & \\
\hline 2 & אתrs & אـمحن & \\
\hline 2 & דتة, & סـ & \\
\hline 2 & מe & حـL & \\
\hline
\end{tabular}




\begin{tabular}{|c|c|c|c|}
\hline 2 & مer & 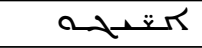 & \\
\hline 2 & i خلיحم & 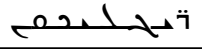 & \\
\hline 2 & il & אـتעل & \\
\hline 2 & vian & אـــ & \\
\hline 3 & Rivif & $c^{2}$ & $\begin{array}{l}\text { פטירין/ (TgPs.J.) פטירי / (TgO) פַטיר (TgNeoph.) } \\
\text { (TgO) }\end{array}$ \\
\hline 3 & reders & $-d x$ & משתיא / מִשתחיָא (TgO, TgPs.J.) \\
\hline 7 & tal & Vo & לוט (FTV) \\
\hline 8 & $\checkmark$ את & $\Delta x$ & \\
\hline 8 & bhing & 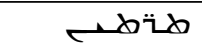 & \\
\hline 8 & iar/inar & $\dot{22 x}$ & \\
\hline 8 & حلuחx & 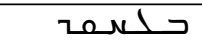 & \\
\hline 9 & ערזם & Iح את & \\
\hline 9 & مiأحى & قتـنـه & \\
\hline 9 & rith & $\pi \sim$ id & \\
\hline
\end{tabular}

Además de esta veintena de coincidencias léxicas, también tenemos en el versículo 4 el uso del mismo sintagma preposicional en ACP y la

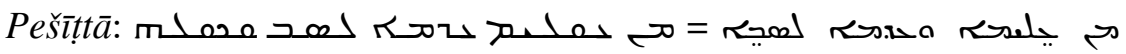
Asimismo, en el versículo 5 tenemos coincidencias, aunque en este caso con las esperables diferencias gramaticales propias entre el registro culto de la Pešntttā y el dialectal de ACP ( $c f$. supra), con las correspondencias respectivas con los targîmîm: Peš $\bar{t} t$ ta $=$ TgO y ACP $=$ TgNeoph.

A modo de resumen. Las diferencias que presenta ACP con respecto a la LXX pueden deberse a expansiones concretas realizadas por el traductor. Sin embargo, lo que parece más probable, de acuerdo con los datos que tenemos de la práctica traductora de los melkitas, es que se deba a la utilización de otras versiones con las que el traductor de ACP revisó su traducción. En este sentido, las coincidencias léxicas o sintagmáticas que se dan entre ACP y la Pešițtā podrían ser la consecuencia de esta práctica de revisión, que sabemos que era habitual entre los traductores melkitas, tanto en la traducciones realizadas a partir de originales griegos como siriacos ${ }^{101}$. Esta labor revisora más que corregir posibles lecturas del origi-

${ }^{101}$ Cf. Mt Sinai Arabic Codex 151, I. Pauline Epistles, ed. Harvey StaAl (Leuven: CorpusSCO, 1983) págs. 40 (n. 24), 45 (n. 14), 138 (n. 8), 145 (n. 8), y Juan Pedro 
nal utilizado para la traducción cumplía la función de revisar el texto con el objetivo de producir una versión lo más perfecta posible.

En el caso de ACP, que recoge una traducción cuyo registro lingüístico es dialectal, lo que perseguía el traductor no era, obviamente, ofrecer una versión de registro elevado, sino un texto que resultase inteligible a las gentes del medio rural entre los que desarrollaban su labor pastoral los monjes de los monasterios cercanos. Para ello, el traductor realizó una versión literal del original griego, cuya traducción resultante cotejó posteriormente con la versión estándar siriaca de la Pešị̂t tă pero sin querer emular en ningún momento ni el registro de esta ni su traducción.

Recibido: 15/01/2017

Aceptado: 13/02/2017

Monferrer-SALA, «An early Fragmentary Christian Palestinian Rendition of the Gospels into Arabic from Mār Sābā (MS Vat. Ar. 13, 9th c.)», Intellectual History of the Islamicate World 1 (2013) págs. 69-113: 71, 73 y 95-96; «The Pauline Epistle to Philemon from Codex Vatican Arabic 13 (Ninth Century CE). Transcription and Study», Journal of Semitic Studies LX:2 (2015) págs. 341-371: 359 y 368, y «Translating the Gospels into Arabic from Syriac: Vatican Arabic 13 Restored Section, Strategies and Goals», Arabica 62:4 (2015) págs. 435-458: 437 y 456. 